\title{
Synthesis of porous ceramics for ceramic biosensors
}

\author{
Vyacheslav Khusnutdinov ${ }^{1-}$, Artem Ulihin $^{1}$ \\ ${ }^{1}$ Institut of Solid State Chemistry and Mechanochemistry, SB RAS, 630090, Russian Federation
}

\begin{abstract}
Highly porous ceramic materials with open porosity are perspective for manufacture of the biosensors. Those materials are used as a framework and open porosity allows to inject a necessary functional components into internal volume. Electroconductive highly porous ceramics on a base of $\mathrm{La}_{1-\mathrm{x}} \mathrm{Ca}_{\mathrm{x}} \mathrm{MnO}_{3}$ with variable composition have acceptable hardness and relatively low sintering temperature (about $1450^{\circ} \mathrm{C}$ ). In recent work samples of highly porous ceramic with the composition of $\mathrm{La}_{1-\mathrm{x}} \mathrm{Ca}_{\mathrm{x}} \mathrm{MnO}_{3}(\mathrm{x}=0.3,0.5$ and 0.7$)$ were obtained by impregnating a carbon nonwoven material with a slip containing presynthesized compounds of the desired composition, followed by annealing at $1415-1450^{i} \tilde{N}$. Obtained materials according to the scanning electron microscopy data have a pore size of up to $100 \mu \mathrm{m}$. The conductivity is $0.5-$ $2.5 \mathrm{~S} / \mathrm{cm}$.
\end{abstract}

\section{Introduction}

The development of ceramic nanocomposite materials for biosensors that provide high accuracy of biopotential measuriments, stability, sensor reliability and low noise level is a problem of great importance for modern medical technologies. For these purposes, composites with mixed ionic electronic conductivity, which are widely used as electrode materials for various electrochemical devices, can be used. For effective use, such a material must have high electrochemical activity, which is determined by the ease of access of electrons and ions to electrochemically active sites. In the literature there is a large number of works on the properties of pure compounds with a mixed ion-electronic character of conductivity [1]. It was shown that the electrophysical characteristics of the composite significantly depend on the morphology of the material and the concentration of the components. To create effective ceramic sensors, it is advisable to use highly porous ceramic matrices, which play the role of a rigid framework, into the pores of which functional components with mixed conductivity can be introduced. Compounds of variable composition $\mathrm{La}_{1-\mathrm{x}} \mathrm{Ca}_{\mathrm{x}} \mathrm{MnO}_{3}$ were used as a material for the ceramic matrix [2-6]. These complex oxides have properties such as electronic conductivity and a relatively low sintering temperature, which makes them promising materials for the manufacture of ceramic frameworks for biosensors. The aim of this work was to study the morphology, character of porosity, and conductivity of highly porous ceramics based on $\mathrm{La}_{1-\mathrm{x}} \mathrm{Ca}_{\mathrm{x}} \mathrm{MnO}_{3}$.

-Corresponding author: V.Khusnutdinov@gmail.com 


\section{Experimental}

Calcium-doped lanthanum manganites $\mathrm{La}_{1-\mathrm{x}} \mathrm{Ca}_{\mathrm{x}} \mathrm{MnO}_{3}(\mathrm{x}=0.3,0.5$ and 0.7$)$ were obtained according to the method described in [7]. A mixture of carbonates of lanthanum, manganese and calcium (chemical pure grade) in the required molar ratios was ground and homogenized using zirconium balls in ethanol at a speed of $1000 \mathrm{rpm}$ for 2 hours. The ratio balls / bulk / ethanol was 100/20/40 by weight. The resulting mixtures were annealed in air at $1300^{\circ} \mathrm{C}$ for 5 hours. Black products were thoroughly ground in an agate mortar and annealed in air at $1400^{\circ} \mathrm{C}$ for 12 hours. Then the samples were ground using zirconium balls under the same conditions as the initial mixture of carbonates.

A mixtures for impregnation consisting of a $5 \%$ aqueous solution of polyvinyl alcohol and obtained powders were prepared. The water content in the suspensions was $30-35 \%$. The resulting slips were impregnated into a nonwoven material based on carbon fibers, followed by squeezing out excess suspensions. The workpieces were dried in air at $100^{\circ} \mathrm{C}$ and annealed for 16 hours at $1470^{\circ} \mathrm{C}$ (samples with $\mathrm{x}=0.3$ and 0.5 ) and at $1415^{\circ} \mathrm{C}$ for a sample with $\mathrm{x}=0.7$.

X-ray phase analysis (XRD) was carried out on a D8 Advance diffractometer using $\mathrm{CuK} \alpha$ radiation and a one-dimensional Lynx - Eye detector with a nickel filter. The diffraction angle $2 \Theta$ is ranging from $10^{\circ}$ to $70^{\circ}$ with a step size of $0.02^{\circ}$ and an accumulation time of $35.4 \mathrm{~s}$. The morphology of the obtained materials was investigated using scanning electron microscopy (SEM) on a HITACHI TM 1000 device. The resistance measuriments were carried out by a four-contact method according to the Van-der-Pauw method.

\section{Results and Discussion}

According to XRD data (Fig. 1), monophasic samples were obtained as a result of synthesis. The reflections are in a good agreement with the PDF data \# 46-513 with an orthorhombic crystal structure (space group Pnma, \# 62). The observed shift in the position of the reflections towards larger angles with increasing calcium content is due to the fact that, in order to maintain the electroneutrality of the compound, the oxidation state of some of the manganese ions increases from +3 to +4 , which leads to a reduction in the lattice parameters. Also, this oxidative transition leads to the disappearance of the (101) reflection at $\mathrm{x}=0.5$ and more [8]. SEM micrographs (Fig. 2) indicate that the ceramic materials obtained after carbon fiber burning and sintering have a highly porous structure with a wide pore size distribution: from submicron size to $100 \mu \mathrm{m}$. Macropores are of a cross-cutting nature and open access for impregnation of the internal volume of materials with organic and aqueous solutions. This makes it possible to modify the inner surfaces and apply various functional coatings. In general, the morphology of the obtained ceramics repeats the structure of the initial carbon support: the material is concentrated around the burnt fibers and at the points of their intersection. On closer inspection (Fig. 2 B), the samples are micron-sized densely sintered particles. Some of the ceramic frame fibers are broken (Fig. 2 D). Most likely, this is due to mechanical action at the stage of impregnation and squeezing of the initial carbon material with a slip. In this regard, these procedures should be carried out carefully, without undue mechanical stress. Estimation of the porosity of the obtained ceramic materials gives a value of $75-85 \%$. Conductivity is $0.5-2.5 \mathrm{~S} / \mathrm{cm}$. The significant difference is probably related to the different degree of filling with the slip of the initial carbon material. 


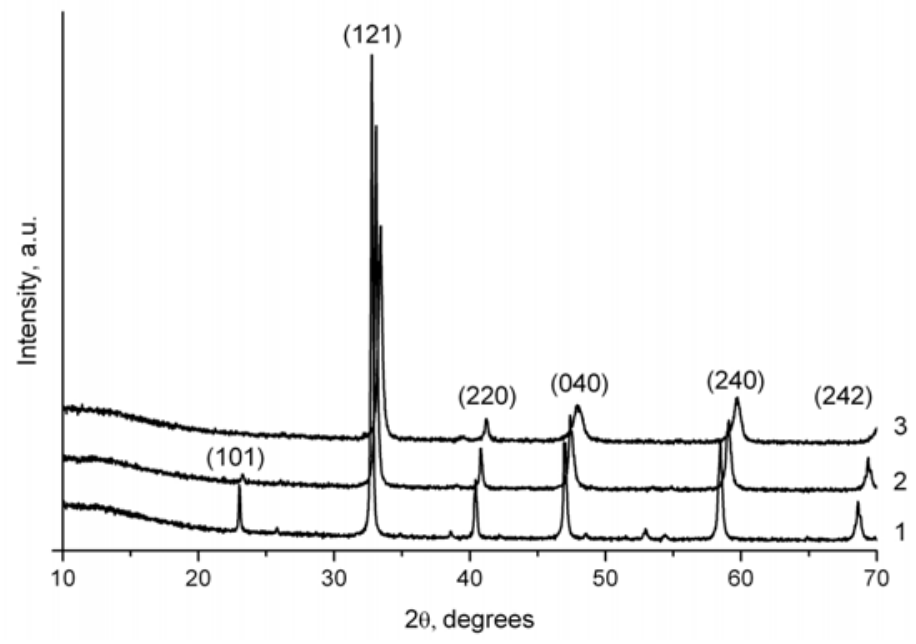

Fig. 1. $\mathrm{XRD}$ patterns of $\mathrm{La}_{1-\mathrm{x}} \mathrm{Ca}_{\mathrm{x}} \mathrm{MnO}_{3}(\mathrm{x}=0.3,0.5,0.7)$ ceramics after sintering at $1400^{\circ} \mathrm{C}$ for $12 \mathrm{~h} .1-$ $\mathrm{x}=0.3,2-\mathrm{x}=0.5,3-\mathrm{x}=0.7$.
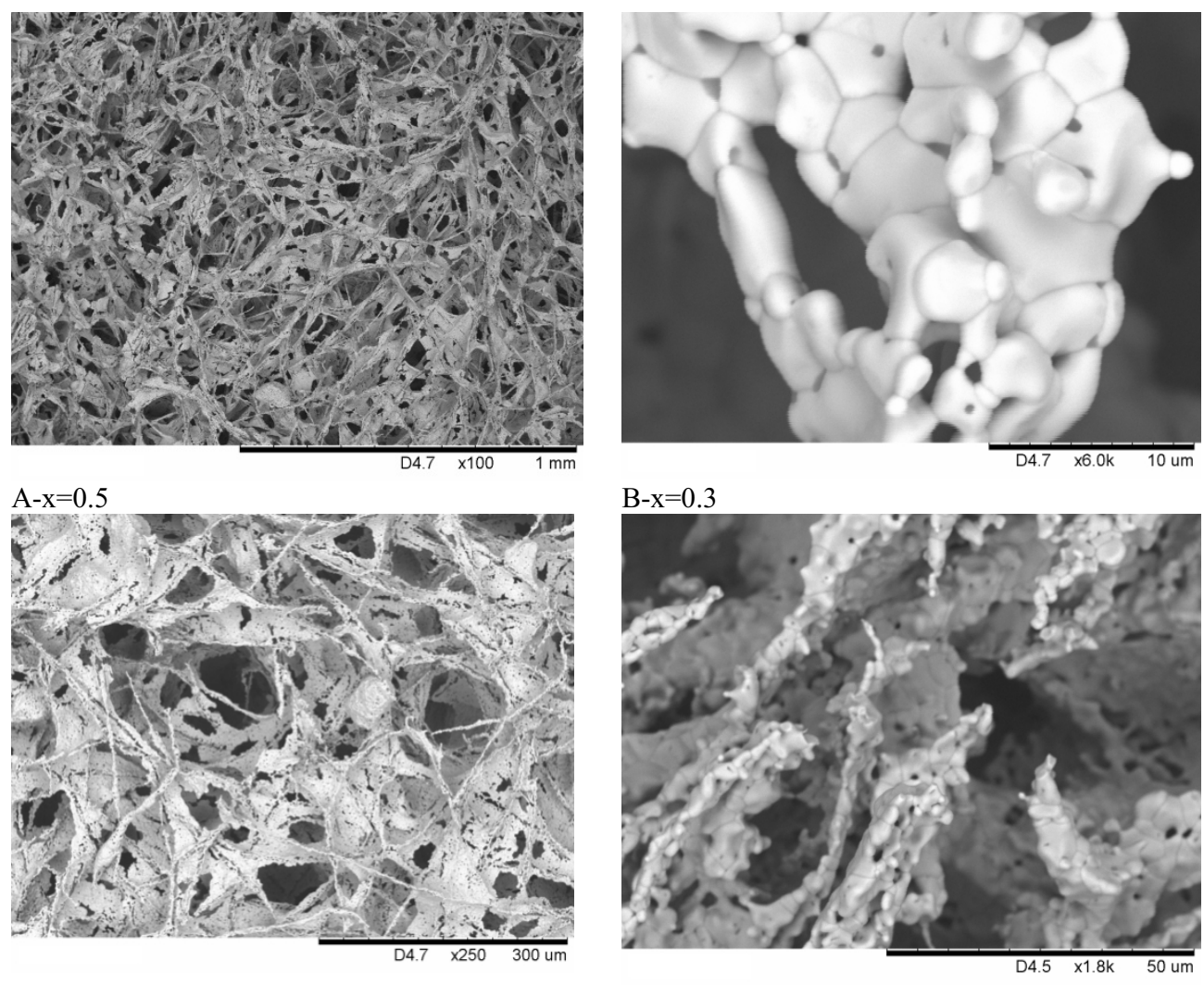

$\mathrm{C}-\mathrm{x}=0.3$

$\mathrm{D}-\mathrm{x}=0.7$

Fig. 2. SEM images of $\mathrm{La}_{1-\mathrm{x}} \mathrm{Ca}_{\mathrm{x}} \mathrm{MnO}_{3}(\mathrm{x}=0.3,0.5,0.7)$ ceramics. 


\section{Conclusion}

As a result of this work, we obtained and studied highly porous ceramic materials based on $\mathrm{La}_{1-\mathrm{x}} \mathrm{Ca}_{\mathrm{x}} \mathrm{MnO}_{3}(\mathrm{x}=0.3,0.5$ and 0.7$)$ with an open nature of pores. Ceramics have electronic conductivity, sufficient strength, and are impregnated with solutions, that allow them to be used to obtain biosensor materials.

The work is supported by the Russian Fund of Basic Research, grant 18-29-11054mk.

\section{References}

1. C.N.R. Rao, J. Gopalakrishnan, New Directions in Solid State Chemistry (Cambridge University Press, 1997)

2. M. Roy, J. Mitchell, A. Ramirez, P. Schiffer, J. Phys.: Condens. Matter 11, 4843 (1999)

3. E. Wollan, W. Koehler, Phys. Rev. 100, 545 (1955)

4. G. Matsumoto, Phys. Soc. Japan 29, 606 (1970)

5. G. Matsumoto, Phys. Soc. Japan 29, 615 (1970)

6. P. Schiffer, A. Ramirez, W. Bao, S-W. Cheong Phys. Rev. Lett. 75, 3336 (1995)

7. N. Thenmozhi, R. Saravanan, Rare Met. (2017)

8. I. Lira-Hernandez, F. Jesus, C. Cortes-Escobedo, A. Bolarin-Miro, J. Am. Ceram. Soc. 93, $3474(2010)$ 